\title{
Assembly of the small ribosomal subunit in yeast: mechanism and regulation
}

\author{
MALIK CHAKER-MARGOT \\ The Rockefeller University, New York, New York 10065, USA \\ Tri-Institutional Program in Chemical Biology, New York, New York 10065, USA
}

\begin{abstract}
The eukaryotic ribosome is made of four intricately folded ribosomal RNAs and 79 proteins. During rapid growth, yeast cells produce an incredible 2000 ribosomes every minute. Ribosome assembly involves more than 200 trans-acting factors, intervening from the transcription of the preribosomal RNA in the nucleolus to late maturation events in the cytoplasm. The biogenesis of the small ribosomal subunit, or 40S, is especially intricate, requiring more than four times the mass of the small subunit in assembly factors for its full maturation. Recent studies have provided new insights into the complex assembly of the $40 S$ subunit. These data from cryo-electron microscopy, X-ray crystallography, and other biochemical and molecular biology methods, have elucidated the role of many factors required in small subunit maturation. Mechanisms of the regulation of ribosome assembly have also emerged from this body of work. This review aims to integrate these new results into an updated view of small subunit biogenesis and its regulation, in yeast, from transcription to the formation of the mature small subunit.
\end{abstract}

Keywords: ribosome; ribosome assembly; small ribosomal subunit; pre-40S

\section{INTRODUCTION}

Ribosomes are large ribonucleoprotein particles that synthesize all proteins in the cell. They are conserved in all domains of life and are composed of both RNA and protein components. Ribosomes are ribozymes that are organized as two asymmetric subunits: the large subunit (LSU), which catalyzes peptide-bond formation, and the small subunit (SSU) that decodes messenger RNA (mRNA). In eukaryotes, ribosomes are composed of four ribosomal RNAs (rRNAs): the $18 \mathrm{~S}$ rRNA, which is part of the SSU, and the 25S (in yeast, $28 \mathrm{~S}$ in humans), 5.8S and 5S rRNAs, which are part of the LSU.

From bacteria to eukaryotes, ribosomes have seen a dramatic increase in complexity, with the appearance of several large eukaryotic expansion segments in the ribosomal RNA, new ribosomal proteins, and extensions of conserved ribosomal proteins (Ben-Shem et al. 2011; Klinge et al. 2011; Rabl et al. 2011). This has been accompanied by the emergence of an elaborate assembly process. Whereas only 20 factors are used for bacterial ribosome biogenesis, most of which are dispensable, more than 200 factors are required to make a eukaryotic ribosome. In eukaryotes, preribosomal RNA features long transcribed spacers-two external ( $5^{\prime}$ and $3^{\prime}$ ETS) and two internal transcribed spacers (ITS1 and ITS2). These are involved in the recruitment of ribosome assembly

Corresponding author: malik.chakermargot@gmail.com

Article is online at http://www.rnajournal.org/cgi/doi/10.1261/rna. 066985.118. factors and help to coordinate the assembly of the ribosomal RNA. The spacers and three of the four rRNAs are transcribed by RNA polymerase I (RNAP I) as one large polycistronic transcript called the $35 \mathrm{~S}$ pre-rRNA in yeast. The $5 \mathrm{~S}$ rRNA is transcribed separately by RNA polymerase III.

Ribosome assembly starts in the nucleolus where the $35 \mathrm{~S}$ is transcribed from approximately 150 tandemly repeated ribosomal DNA (rDNA) loci. There, ribosome assembly factors bind cotranscriptionally to the nascent RNA chain and start chaperoning and processing the pre-rRNA. This leads to the formation of two large multicomponent complexes: the SSU and LSU processomes. Initially, these particles were visualized by Miller chromatin spreads as large terminal structures at the end of the nascent pre-rRNA (Miller and Beatty 1969) from actively transcribed rDNA loci. The SSU and LSU processomes are later separated from one another by cleavage events in ITS1, at sites A2 and A3 (Udem and Warner 1972). SSU and LSU maturation then proceeds independently, first in the nucleolus, later in the nucleoplasm, and finally in the cytoplasm. During maturation, transcribed spacers have to be excised, pre-rRNA has to be modified and chaperoned, and assembly factors must coordinate the recruitment

(C) 2018 Chaker-Margot This article is distributed exclusively by the RNA Society for the first 12 months after the full-issue publication date (see http://rnajournal.cshlp.org/site/misc/terms.xhtml). After 12 months, it is available under a Creative Commons License (Attribution-NonCommercial 4.0 International), as described at http://creativecommons.org/licenses/ by-nc/4.0/. 
and incorporation of ribosomal proteins. Chemical modification of the pre-rRNA is catalyzed by small nucleolar RNA (snoRNA), as reviewed in Watkins and Bohnsack (2012). Box C/D snoRNAs guide the 2'-O methylation of ribose groups in the pre-rRNA, whereas box H/ACA snoRNAs direct the conversion of specific uracil bases of the pre-rRNA to pseudouracil.

While later steps in ribosome biogenesis are becoming better understood, there has been a relative lack of biochemical and structural information on the assembly of the SSU. Recent cryo-EM structures of the SSU processome and pre$40 \mathrm{~S}$ particles, as well as biochemical and genetic work studying small ribosomal subunit biogenesis factors, have provided insights into the assembly of this particle in the yeast Saccharomyces cerevisiae. This review aims to summarize all these recent results and offer an updated model of small ribosomal subunit biogenesis in yeast, from transcription of the rRNA to the formation of the mature SSU. It will also discuss the current understanding of how ribosome biogenesis is regulated and connected to other cellular processes.

\section{TRANSCRIPTION AND ASSEMBLY OF THE SSU PROCESSOME}

Ribosome assembly begins with the transcription of rDNA in the nucleolus by RNA polymerase I (RNAP I). RNAP I is responsible for the transcription of the $35 \mathrm{~S}$ pre-rRNA. Unlike RNA polymerase II, which transcribes mRNA, RNAP I requires only four factors to initiate transcription at the rDNA promoter. The architecture of RNAP I and the regulation of its activity by transcriptional factors have been reviewed previously (Schneider 2012). RNA polymerase I possesses 14 subunits, two more than RNAP II. These additional subunits, Rpa34 and Rpa49, are homologous to the TFIIF dimer that binds RNAP II during preinitiation complex formation, suggesting their integration in RNAP I facilitates efficient transcription initiation (Engel et al. 2013). Transcription initiation first requires binding of RNA polymerase I to Rrn3, which renders the enzyme transcription competent (Fig. 1A; Engel et al. 2016; Pilsl et al. 2016). The complex is subsequently recruited to the promoter DNA by the three-subunit core factor complex, leading to promoter melting (Fig. 1A; Engel et al. 2017; Han et al. 2017; Sadian et al. 2017).

As the RNA is transcribed, many factors assemble on the nascent preribosomal RNA, thereby forming the SSU processome. The SSU processome, along with its LSU counterpart, was initially visualized as a terminal structure that forms on nascent pre-rRNA of actively transcribed rDNA (Miller and Beatty 1969). These structures were later defined as containing the U3 snoRNA and many ribosome assembly factors (Dragon et al. 2002; Grandi et al. 2002). Included in those assembly factors were large multiprotein complexes which could also be isolated individually: UtpA, UtpB, and UtpC. The U3 snoRNA is a box C/D snoRNA that interacts with box $\mathrm{C} / \mathrm{D}$ proteins and a U3 specific chaperone, Rrp9
(Venema et al. 2000). Segments of U3 snoRNA were proposed to base pair with the pre-rRNA: The $3^{\prime}$ and $5^{\prime}$ hinges base pair with the $5^{\prime}$ external transcribed spacer ( $5^{\prime}$ ETS), whereas box $\mathrm{A}$ and $\mathrm{A}^{\prime}$ form a duplex with sequences of the 18S (Beltrame and Tollervey 1995; Sharma and Tollervey 1999; Dutca et al. 2011; Marmier-Gourrier et al. 2011).

Later work showed that the assembly of the SSU processome was partially hierarchical with UtpA and UtpB beginning the process and being required for the subsequent additions of factors (Pérez-Fernández et al. 2007, 2011). The SSU processome has been shown to be the result of a stepwise assembly of ribosome biogenesis factors on the nascent preribosomal RNA (Chaker-Margot et al. 2015; Zhang et al. 2016). It is governed by the specific recruitment of protein factors to RNA elements in a stable manner as well as the transient binding of some factors, mainly enzymes (Fig. 1A). The transcription of the $5^{\prime}$ ETS leads to the recruitment of the large complexes UtpA and UtpB, the U3 snoRNP and multiple other proteins, forming the $2 \mathrm{MDa} 5^{\prime}$ ETS particle. In vivo crosslinking data and structural information showed that, within this particle, UtpA has a role in stabilizing the early helices of the spacer RNA while UtpB stabilizes the U3 snoRNA-5'ETS interactions (Hunziker et al. 2016; Kornprobst et al. 2016; Chaker-Margot et al. 2017; Sun et al. 2017).

The $18 \mathrm{~S}$ rRNA can be subdivided into four domains: the $5^{\prime}$ domain, the central domain, the $3^{\prime}$ major domain, and the $3^{\prime}$ minor domain. The $3^{\prime}$ major domain forms the so-called "head" of the SSU while the $3^{\prime}$ minor domain consists mainly of the long helix 44, which rests on top of the other domains at the subunit interface. Domains are held together in part by a tertiary structure element called the central pseudoknot, where segments from the $5^{\prime}$ end and the middle of the $18 \mathrm{~S}$ base pair with each other. The transcription of the $5^{\prime}$ domain induces the recruitment of $5^{\prime}$ domain binding proteins, Enp2, Lcp5, or Bfr2 (Soltanieh et al. 2014; Bammert et al. 2016). The DEAD-box proteins Dbp4 and Dbp8 are also recruited at this stage. Since they are absent from later SSU processome particles, these proteins likely have a transient role in SSU assembly. Dbp4 has been shown to be involved in the unwinding of the U14 snoRNA (Koš and Tollervey 2005) from the pre-rRNA, and to interact with Enp2 and Bfr2 (Soltanieh et al. 2015). U14 snoRNA is an essential box C/D snoRNA that guides the $2^{\prime}-O$ methylation of nucleotide 414 in the $5^{\prime}$ domain (Liang and Fournier 1995) and is required for cleavage at sites A0 and A2. Similarly, Dbp8 and its cofactor Esf2 (Granneman et al. 2006), also recruited by the $5^{\prime}$ domain, may have a role in the removal of other snoRNAs involved in $5^{\prime}$ domain maturation.

Similar to the $5^{\prime}$ domain, the incorporation of the central domain leads to the recruitment of several factors that bind the central domain directly, such as the $\mathrm{KH}$-domain containing protein Krrl and its interactor Kril, the UtpC complex (Lin et al. 2013), Rrp5 (Lebaron et al. 2013) and its partners Noc1/Noc2. Rok1 and Utp23 are also recruited to the central 


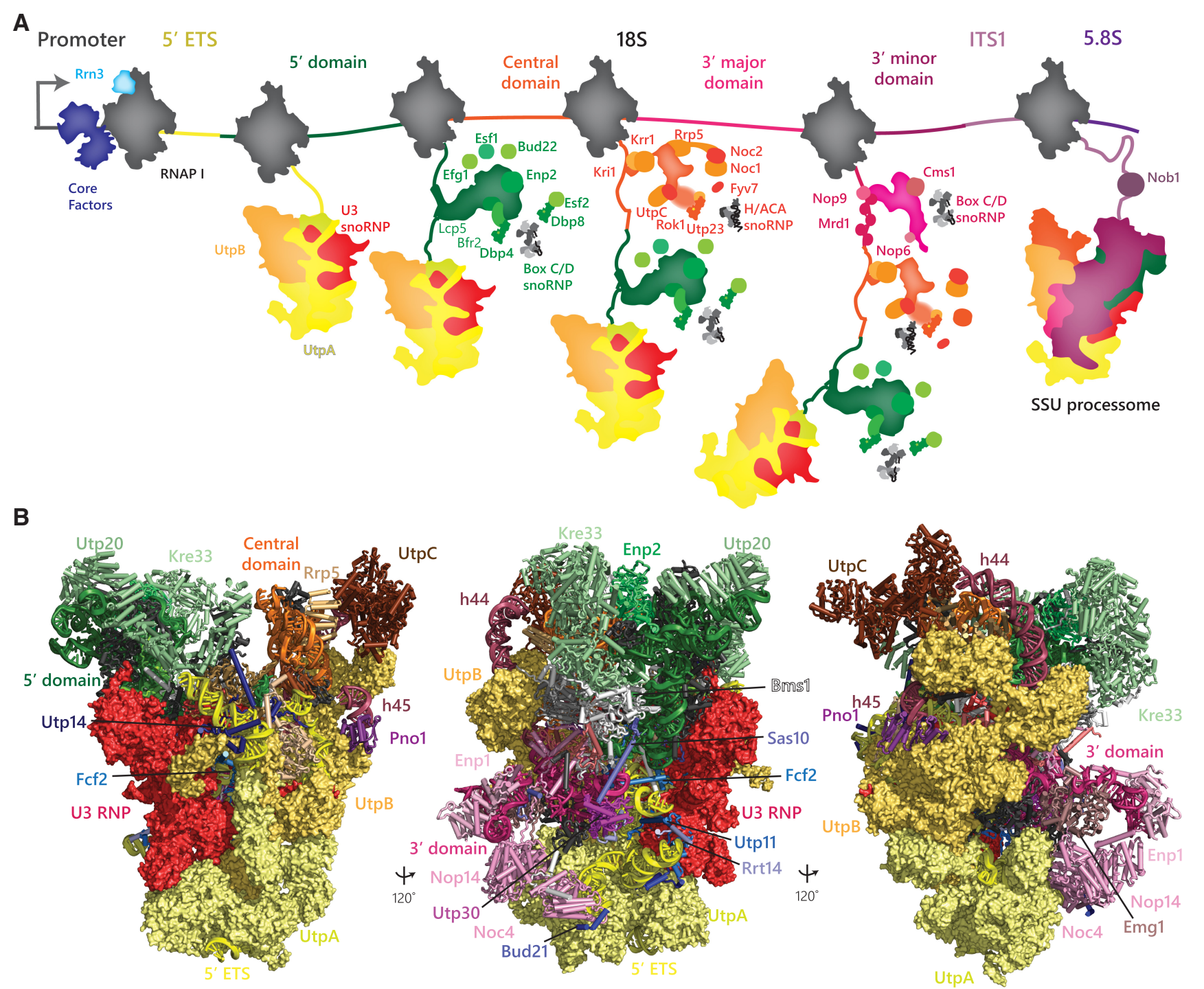

FIGURE 1. Assembly model of the small subunit processome. (A) Schematic representation of preribosomal RNA transcription by RNA polymerase I and cotranscriptional assembly of the SSU processome. The transcription of the $5^{\prime}$ ETS leads to the formation of the $5^{\prime}$ ETS particle. The addition of subsequent $18 \mathrm{~S}$ domains recruits a number of factors but only after the completion of the entire $18 \mathrm{~S}$ can the SSU processome form. Factors are colored correspondingly with their recruitment stage. (B) Views of the S. cerevisiae SSU processome (PDB: $5 \mathrm{WLC}, 5 \mathrm{WYJ}$ ) rotated by $120^{\circ}$. The $5^{\prime}$ ETS is shown in yellow and is bound by UtpA (pale yellow), UtpB (orange yellow), and U3 snoRNP (red). Domains of the 18S rRNA are shown in green ( $\left.5^{\prime}\right)$, orange (central), bright pink ( $3^{\prime}$ major), and dark pink ( $3^{\prime}$ minor) with associated proteins in similar shades.

domain, both of which are involved in the dissociation of the essential box H/ACA snoRNA snR30 from its binding site in expansion segment 6 (Wells et al. 2017). Consistent with this, box H/ACA snoRNP proteins are recruited to the central domain, indirectly suggesting that snR30 is also recruited at this stage of transcription (Fig. 1A).

The $3^{\prime}$ domain recruits the proteins Mrd1 and Nop9 which both have RNA binding domains (Segerstolpe et al. 2013; Wang and Ye 2016). Interestingly, biochemical data suggests that Mrd1 and Nop9 transiently bind after the transcription of the $3^{\prime}$ domain but leaves before the formation of the complete SSU processome (Chaker-Margot et al. 2015; Zhang et al. 2016). In vivo crosslinking data also showed that
Mrd1 binds part of the sequences that form the central pseudoknot (Segerstolpe et al. 2013). Similarly, biochemical data suggests that Nop9 binds the same region of the 18S (Wang and Ye 2016). Therefore, Mrd1 and Nop9 may have a role in chaperoning this important RNA element during transcription to prevent premature RNA folding states before later factors are recruited and induce Mrd1 and Nop9 removal.

The completion of the $3^{\prime}$ minor domain leads to the recruitment of many protein factors. EM studies have shown that many of these proteins form the outer shell of the SSU processome (Fig. 1; Kornprobst et al. 2016; Barandun et al. 2017; Chaker-Margot et al. 2017; Cheng et al. 2017; Sun et al. 2017). Those include helical repeat proteins such as 
Nop14, Noc4, Rrp12, and Utp20, the acetyltransferase Kre33, the methylase Emg1, the GTPase Bms1 and its cofactor Rcl1, the DEAH box helicase Dhr1 and its cofactor Utp14, and Pno1 (Dim2), a KH-domain containing protein that interacts with Nob1. Nob1 is recruited with the addition of ITS1, consistent with its role as the D-site endonuclease (Fatica et al. 2004).

Taken together, these data point to a model of early SSU subunit assembly that initially involves the formation of a $5^{\prime}$ ETS platform and the subsequent recruitment of factors involved in the individual maturation of $18 \mathrm{~S}$ domains. With the completion of the $18 \mathrm{~S}$, these domains may fold into a more compact structure, with the concomitant recruitment of a new wave of factors (Fig. 1A). It should be noted that this model for SSU processome assembly relies broadly on biochemical data obtained from overexpressed truncated pre-rRNAs (Chaker-Margot et al. 2015; Zhang et al. 2016). The timescale at which these experiments are performed far exceeds the short time of SSU processome assembly in vivo, and may not capture the transient interactions occurring endogenously. It will be important to study this process with methods that are better suited to capture the dynamics of SSU processome assembly.

\section{STRUCTURE AND FUNCTION OF THE SSU PROCESSOME}

Recent structures of the SSU processome obtained by cryoelectron microscopy have provided new insights into the roles of the many assembly factors present in this nucleolar supercomplex. The successive structures at increasing resolution have elucidated the basic architecture of this assembly intermediate (Kornprobst et al. 2016; Chaker-Margot et al. 2017; Sun et al. 2017), and more recently revealed the extensive network of interactions between ribosome assembly factors and the preribosomal RNA (Barandun et al. 2017; Cheng et al. 2017). This review focuses on the SSU processome structure from $S$. cerevisiae, as it is the most complete (Barandun et al. 2017). While a large portion of the entire particle was visualized, it is important to highlight that a significant number of proteins, whose presence was confirmed by mass spectrometry and gel electrophoresis, were not seen (partially or entirely), likely due to their high flexibility or particle instability. Furthermore, while the structures of the SSU processome have allowed for the rationalization of biochemical and genetic data, it remains to be determined if the isolated particles are maturation competent or not (KosBraun et al. 2017), since the S. cerevisiae SSU processomes were isolated from nutrient depleted (Barandun et al. 2017) and Mtr4 or Dhr1-depleted cells (Sun et al. 2017).

The SSU processome is a globular particle that can be described as comprising two lobes with a lateral extension, resting on a base (Fig. 1B). At the base of the particle, UtpA binds the first half of the $5^{\prime}$ ETS and seemingly serves as structural platform, consistent with prior data (Pérez-Fernández et al.
2007; Hunziker et al. 2016). Above that, the $5^{\prime}$ and $3^{\prime}$ hinges of the U3 snoRNA base pair with the $5^{\prime}$ ETS forming two RNA duplexes. UtpB and U3 snoRNP proteins stabilize these duplexes. From this core, proteins of the $5^{\prime}$ ETS particle extend outward to bind neighboring proteins and RNA elements. The $5^{\prime}$ domain forms one lobe of the particle. There, the pre-rRNA is encapsulated by the dimer of the acetyltransferase Kre33, the beta propeller Enp2, and the helical repeat protein Utp20. The central domain forms the other lobe of the particle and interacts with several assembly factors: the UtpC complex, Rrp5, and Krr1. The region of the central domain between nucleotides 600 and 850, which includes expansion segment 6 and the snR30 binding site, could not be visualized. The $3^{\prime}$ domain is located in the lateral extension of the structure and is partially unfolded. In the visible part of this region, helical repeat proteins Nop14, Noc4, and Enp1 form a large complex that sits near the partially unfolded $3^{\prime}$ domain. Utp30 and a dimer of the methylase Emg1 interact with the rest of this domain.

The structures of the SSU processome have revealed the diversity of roles taken by early ribosome assembly factors. The roles of SSU processome components can be divided into a few broad categories: protection or stabilization of RNA elements, bridging factors, and enzymes. Several factors seem to have a role in protecting RNA elements from degradation or from forming incorrect or premature tertiary structures. Utp20, Rrp5, Enp1, Krr1, and Pno1 are all examples of such factors. To prevent the $18 \mathrm{~S}$ domains from prematurely forming a pseudomature conformation, ribosome assembly factors bind RNA elements forming or located near the central pseudoknot in the mature particle. Interactions between these RNA elements and assembly factors stabilize nonmature conformations. Proteins such as Bms1, Nop14, Imp4, and Faf1 use extended structural elements to stabilize the box $\mathrm{A}$ and box $\mathrm{A}^{\prime}$ RNA duplexes between $5^{\prime}$ and central domain sequences and the U3 snoRNA. These $5^{\prime}$ and central domain sequences are near-or part of, for the $5^{\prime}$ domain sequence-the central pseudoknot in the mature structure. Similarly, helix 44 is partially unfolded and stabilized by Mpp10, another extended protein, distancing it from other RNA elements. This focus on elements near the central pseudoknot prevents the premature formation of this structure and allows the individual domains to mature further before their tertiary interactions form.

Another set of ribosome assembly factors adopt very extended conformations and are presumably very flexible when not incorporated in the SSU processome: Sas10, Utp11, and Fcf2. These specialized proteins are mostly made of helical segments that interact with protein and RNA elements throughout the structure, sometimes separated by linkers that span 100 to $200 \AA$. This could serve as a structural support for the organization of this particle. As the SSU processome assembles, these early factors might guide the relative positioning of later ribosome assembly factors and the subsequently forming pre-rRNA domains. 


\section{FROM THE SSU PROCESSOME TO PRe-40S PARTICLES}

SSU processome particles must undergo several significant structural and compositional changes to mature into pre$40 \mathrm{~S}$ particles, which adopt a near-mature state. The domains of the $18 \mathrm{~S}$ rRNA in the SSU processome are kept separated, in part by the concerted stabilization of nonmature RNA elements, which are later situated near the central pseudoknot (Fig. 2A-C). Maturation of the SSU processome will therefore require several steps including the formation of the central pseudoknot and RNA cleavage at site A1 (between the 5' ETS and the 18S), and site A2 (in ITS1), unwinding of the U3-18S duplexes, removal of many ribosome assembly factors, including the entire $5^{\prime}$ ETS particle, and the inclusion of new ribosomal proteins and assembly factors, such as Tsr1, Rio2, and Ltv1, for nuclear export.

The most critical steps for SSU processome maturation are the cleavages of the A1 and A2 sites, formation of the central pseudoknot, and removal of the $5^{\prime}$ ETS particle. This requires the base-pairing of U3 snoRNA and the central pseudoknot sequences to be unwound. This is partially catalyzed by the DEAH-box helicase Dhr1 (also known as Ecm16) (Sardana et al. 2015). The structure of the SSU processome obtained from Dhr1-depleted cells (Sun et al. 2017) looks nearly identical to SSU processomes purified from starved cells (Barandun et al. 2017), where Dhrl and its cofactor Utp14 (Sardana et al. 2014) are present (Fig. 2E). It is possible that conformational changes have to occur in order for the helicase to engage its substrate. Previous data suggests that Utp24 cleaves both the A1 and A2 sites (Bleichert et al. 2006; Wells et al. 2016). In the structures of the SSU processome, neither the A1 nor the A2 site can be accessed by the active site of Utp24. The A1 site is protected by Utp14/ Sof1/Utp7, raising the possibility that Utp14 might direct Dhr1 to the U3 box A-18S duplex (Fig. 2D,E). Crosslinking studies suggest that Dhr1 may only unwind the pre-18S:U3
A
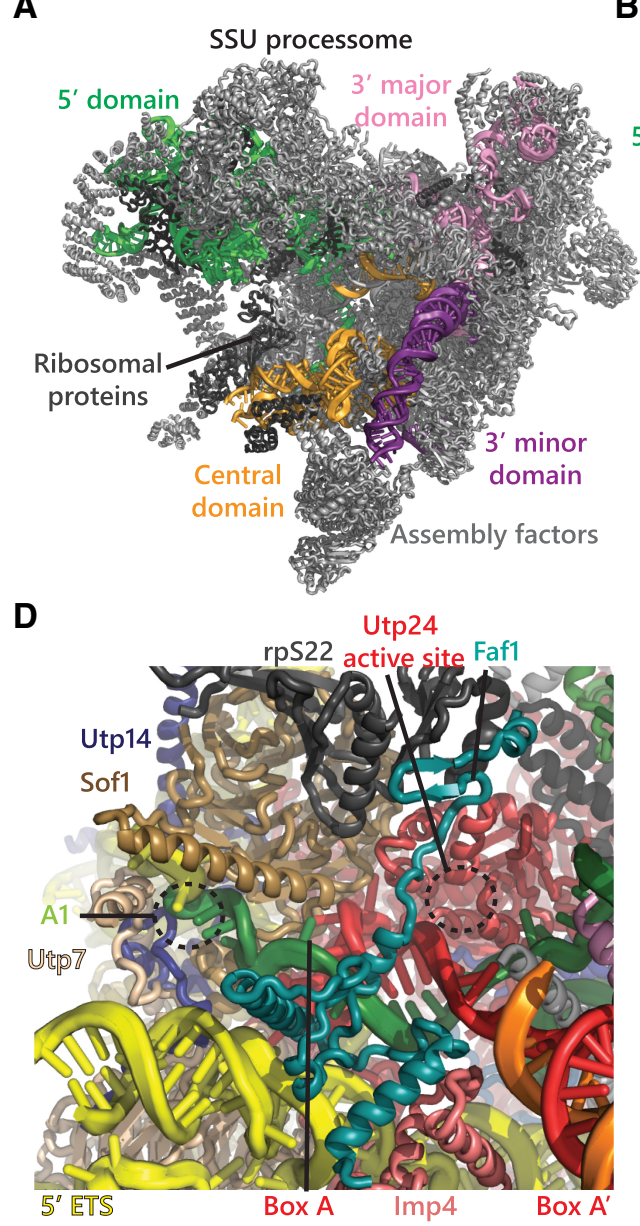

B

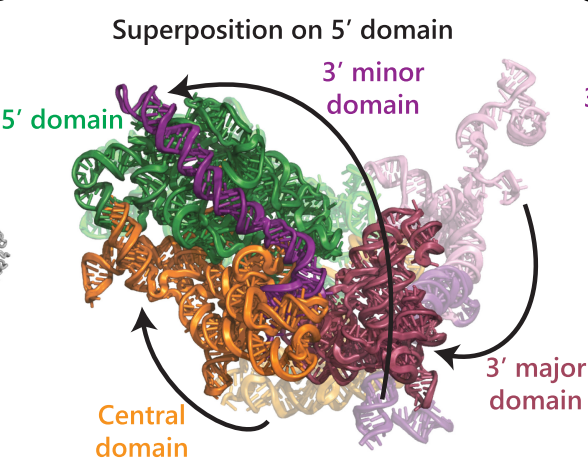

E

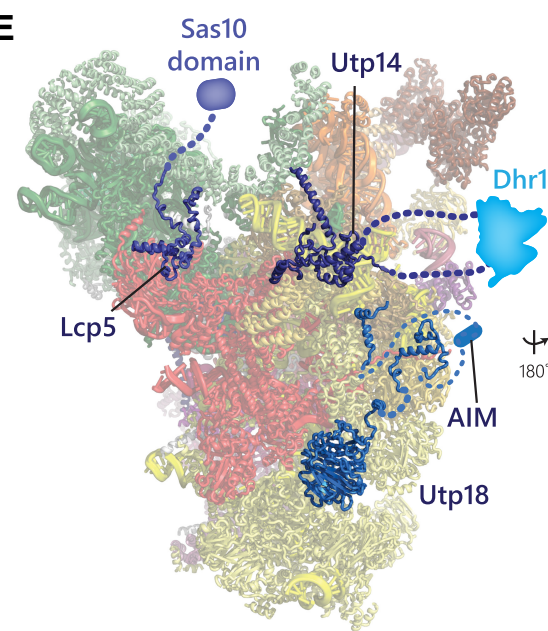

C
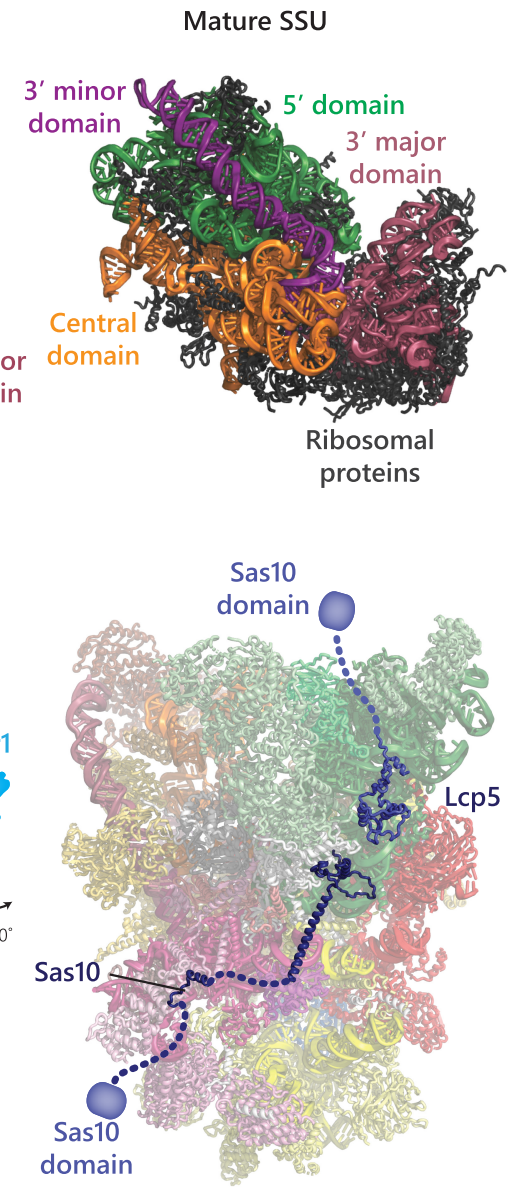

FIGURE 2. Maturation of the small subunit processome. $(A-C)$ Comparative views of the domains of the $18 \mathrm{~S}$ rRA in the SSU processome (PDB: 5WLC, 5WYJ) and the mature small subunit (PDB: 4V88). Domains have to undergo large rotational movement in order to adopt their mature conformation as shown in $B$. In $B, 18 \mathrm{~S}$ domains in their SSU processome conformation are transparent. $(D)$ Cartoon representation of the A1 cleavage site in the SSU processome. It is protected by Sof1, Utp7, and Utp14, while the active site of the nuclease Utp24 is prevented from accessing the substrate by Faf1. (E) Cartoon representation of Utp18, Sas10, Lcp5, and Utp14 in the SSU processome. Utp18, Sas10, and Lcp5 are involved in recruiting the RNA degradation machinery through their AIM motif or the Sas10 domains, respectively. Utp14 is bound to Dhr1, which is flexibly attached to the particle. 
snoRNA duplex at box A but not A' (Sardana et al. 2015), suggesting that another helicase could unwind the box $\mathrm{A}^{\prime}$ to remove U3 snoRNA from the preribosomal particle.

Cleavage and rearrangement of the preribosomal RNA leads to the recruitment of a number of ribosomal proteins whose binding sites were not yet formed. This includes uS3 and eS26, which bind the $18 \mathrm{~S}$ between the beak and the body, and at the shoulder, respectively. These proteins are imported into the nucleus while bound to dedicated chaperones -Yar1, for uS3; and Tsr2, for eS26 (Holzer et al. 2013; Schütz et al. 2014; Mitterer et al. 2016). It is unclear how the handover from chaperone to pre-40S occurs.

Concomitant to the dramatic rearrangement of pre-18S domains, and the association of ribosomal proteins and late ribosome assembly factors, the entire 5'ETS particle has to be removed and degraded, a critical step to recycle ribosome assembly factors. This is thought to be accomplished by the exosome, given that mutations to the exosome core or its associated cofactors lead to dramatic accumulation of the cleaved 5' ETS (Allmang et al. 2000). The mechanism by which this process is regulated is not fully understood, but the SSU processome contains several domains that could recruit the RNA degradation machinery, providing some insights into how the exosome could be recruited. Just like the LSU assembly factor Nop53, UtpB-complex subunit Utp18 contains an arch interacting motif (AIM), which can bind the noncatalytic domain of the exosome-associated helicase Mtr4 (Fig. 2E; Thoms et al. 2015). This helicase binds the exosome and has a role in unwinding RNA elements and feeding these to the catalytic sites of the nuclear exosome (De la Cruz et al. 1998). Furthermore, two factors of the SSU processome, Sas10 and Lcp5, contain domains that have high homologies to the exosome cofactor Rrp47 (Fig. 2E; Costello et al. 2011). However, unlike in the LSU maturation pathway where recruitment of the exosome is used for precise processing of the $5.8 \mathrm{~S}$ rRNA, here the recruitment is thought to lead to the degradation of the entire $5^{\prime}$ ETS.

\section{CYTOPLASMIC EXPORT AND LATE STAGES OF MATURATION}

Prior to nuclear export, the core of pre-40S particles is in a near-mature state but remains associated with several ribosome assembly factors that protect important functional sites of the maturing SSU. Importantly, the $3^{\prime}$ domain, which forms the head of the SSU, is still partially unfolded at this stage. Factors bound to these pre-40S particles include the SSU processome components Enp1, Pno1, and Rrp12, as well as later proteins such as Rio2, Ltv1, Dim1, or Tsr1, which bind the pre-40S particle in the nucleus (Fig. 3; Schäfer et al. 2003). Notably, Tsr1 is an inactive GTPase (McCaughan et al. 2016) that has high homology with Bms1 but lacks its catalytic activity. Recent high-resolution structures of pre-40S particles have revealed the interactions between some of these factors and the maturing SSU (Heuer et al. 2017; Scaiola et al. 2018). Rio2, Tsr1, and Dim1 are located on the subunit facing side of the pre-40S, near the decoding site. Enp1 is placed on the solvent facing side, interacting with the beak structure, analogous to its position in the SSU processome. A peptide of Ltv1 is bound on the solvent exposed side of Enp1. Finally, Pnol is positioned at the end of helix 45, on the shoulder of the maturing SSU. Despite being bound to the particle, Nob1 is flexibly attached and not resolved in the structures of the pre-40S.

Export of pre-40S particles to the cytoplasm has been shown to rely on multiple overlapping pathways (Fig. 3). Several assembly factors including Rio2, Ltv1, and Pno1 have predicted nuclear export signals (NES) that can potentially recruit the nuclear export machinery. The main exportin in this pathway is the karyopherin Crm1/Xpo1. Crm1 typically binds NES-containing proteins and RanGTP, thereby forming a ternary complex (Fung et al. 2015). Crm1, as any karyopherin, then interacts with the FG nucleoporins, which leads to cargo-export (Hayama et al. 2017). Recent studies have shown that the SSU assembly factor Slx9 binds RanGTP and NES-containing protein Rio2, which cooperatively recruits Crm1. The Mex67-Mtr2 dimer, which has been shown to be important for pre-60S export, has an additional role in pre-40S export (Faza et al. 2012). It was also proposed that Rrp12 can interact with FG nucleoporins (Oeffinger et al. 2004). With multiple proteins having the ability to interact with Xpo1 and RanGTP, Mex67-Mtr2, or with the FG-Nucleoporins (Nups) directly, the pre-40S can use multiple pathways to achieve nuclear export. Such redundancy in the presence of NES and interaction with the nuclear pore complex may help efficient export of pre-40S subunits, given that NES-exportin interactions are notoriously weak (Kutay and Guttinger 2005).

Interestingly, the pre-40S associated NES-containing proteins Ltv1 and Rio2 each have binding sites (Granneman et al. 2010; Heuer et al. 2017; Scaiola et al. 2018) that are not compatible with the SSU processome. Ltv1 occupies the same binding site on Enp1 as the early factor Nop14 (Barandun et al. 2017). Rio2 occupies a site that has not yet formed in the SSU processome, between the head and the body of the SSU. This may prevent premature recruitment of Crm1. Conversely, Pno1, which is also proposed to carry an NES, is stably associated with the SSU processome, but the proposed NES sequence is involved in an interaction with the early factor Utp21, which could also prevent premature Crm1 association (Fig. 3).

Once in the cytoplasm, several factors leave the pre-40S particles. Hrr25 phosphorylates Enp1 and Ltv1, leading to their dissociation (Schäfer et al. 2006; Ghalei et al. 2015). Rio2 likely also dissociates from pre-40S in an ATPase dependent manner (Ferreira-Cerca et al. 2012). The placement of Rio2 between the head and the body of the maturing SSU suggests it may be sensing the formation of the $3^{\prime}$ domain.

Pre-40S particles associate with mature $60 \mathrm{~S}$ subunits to form 80S-like complexes (Lebaron et al. 2012; Strunk et al. 


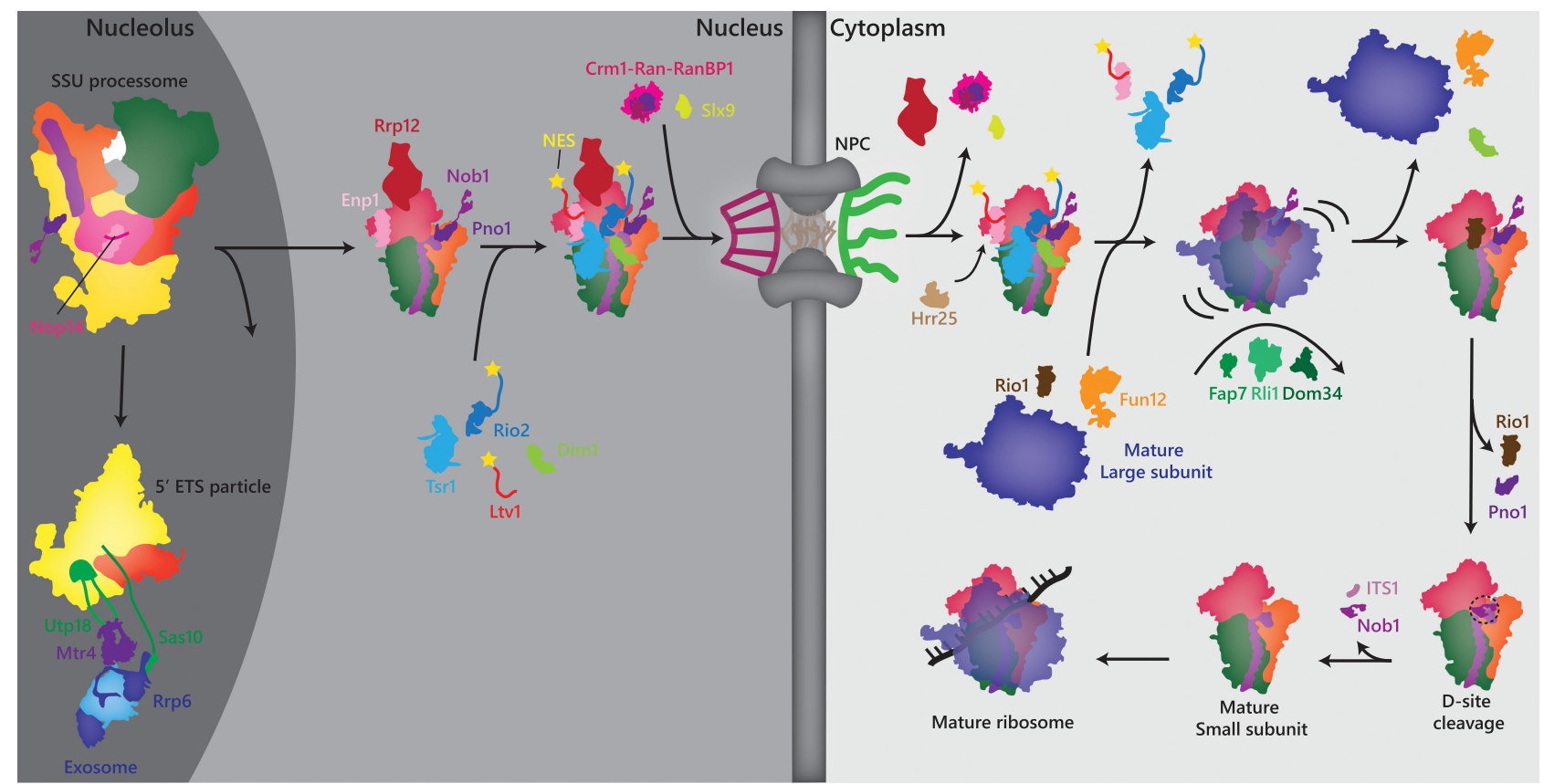

FIGURE 3. Cytoplasmic export and maturation of pre-40S particles. Overview of small subunit biogenesis from late nucleolar stage to the final cytoplasmic step. Pre-40S particles form in the nucleus and are exported by several redundant pathways. After several factors leave in the cytoplasm, $80 \mathrm{~S}$ like complexes form. Their dissociation leads to D-site cleavage and mature small subunit formation.

2012). The formation of these 80 S-like complexes is promoted by the assembly factor and ATPase Riol (Turowski et al. 2014) and the translational GTPase Fun12 (eIF5B) (Lebaron et al. 2012). During translation, Fun12 enhances subunit joining and Met-tRNA binding at the beginning of translation. However, here, Fun12 is involved in the quality control of the pre-40S subunit. Dissociation of these 80 Slike complexes is dependent on the activity of the adenylate cyclase Fap7 (Ghalei et al. 2017), the ATPase Rio1 and GTP hydrolysis by Fun12 (Ferreira-Cerca et al. 2014). Fap7 has been suggested to induce pseudotranslocation of this $80 \mathrm{~S}$ like complex (Ghalei et al. 2017). Its departure from the complex is promoted by ATP hydrolysis, which may also induce Dim1 dissociation. 80S-like complex separation is promoted by Rli1 and Dom34, which are involved in mature 80S dissociation during translation termination (Strunk et al. 2012). The ATPase activity of Riol is also important for dissociation of the 80S-like complexes. In vivo crosslinking data shows Riol binds between the head and body of the pre-40S, in a similar fashion to Rio2. This points to Rio2 and Rio1 acting sequentially in SSU assembly as sensors of the head formation and the translation competence of the SSU, respectively.

Complex dissociation is followed by cleavage at the D-site. Pno1 is strategically located near the cleavage site in the pre$40 \mathrm{~S}$ structure while Nob1 is flexibly attached to the particle (Heuer et al. 2017; Scaiola et al. 2018). This suggests that Pno1 may protect the site until the particle is mature, at which point it either presents the substrate to Nob1, or dissociates from the particle, leading to cleavage. Nob1, which binds ITS1 (Granneman et al. 2010), is thought to leave with the cleaved product.

\section{REGULATION OF RIBOSOME BIOGENESIS BY THE TOR PATHWAY AND THE CELL CYCLE}

Given the importance of constant ribosome production in a growing cell, the biogenesis of ribosomes is tightly regulated to account for energetic needs and nutrient availability. Regulation of ribosome biogenesis occurs at several levels: the transcription of rRNA by RNAP I, the transcription of ribosomal protein genes by RNAP II, the activity of assembly factors. Recent insights into the regulation of ribosome assembly have shown the preponderant role of the TOR and Casein kinase 2 (CK2) activities, as well as other factors in this process (Fig. 4).

Nutrient availability regulates TOR activity: When nutrients are abundant, TOR is activated and phosphorylates several downstream effectors. One downstream target of TOR is RNA polymerase $\mathrm{I}$, which is therefore regulated in response to the nutrient state. In response to starvation, RNAP I can dimerize, preventing its association with the initiation factor Rrn3 and therefore transcription. It was suggested that this is partly regulated by phosphorylation of Rrn3 (Torreira et al. 2017). This elegant mechanism permits a rapid response to changing environmental factors while storing the enzyme. The assembly factor Riol is involved in the phosphorylation of a conserved tyrosine on Rpa43, a subunit of RNAP I. This phosphorylation promotes rDNA transcriptional repression 


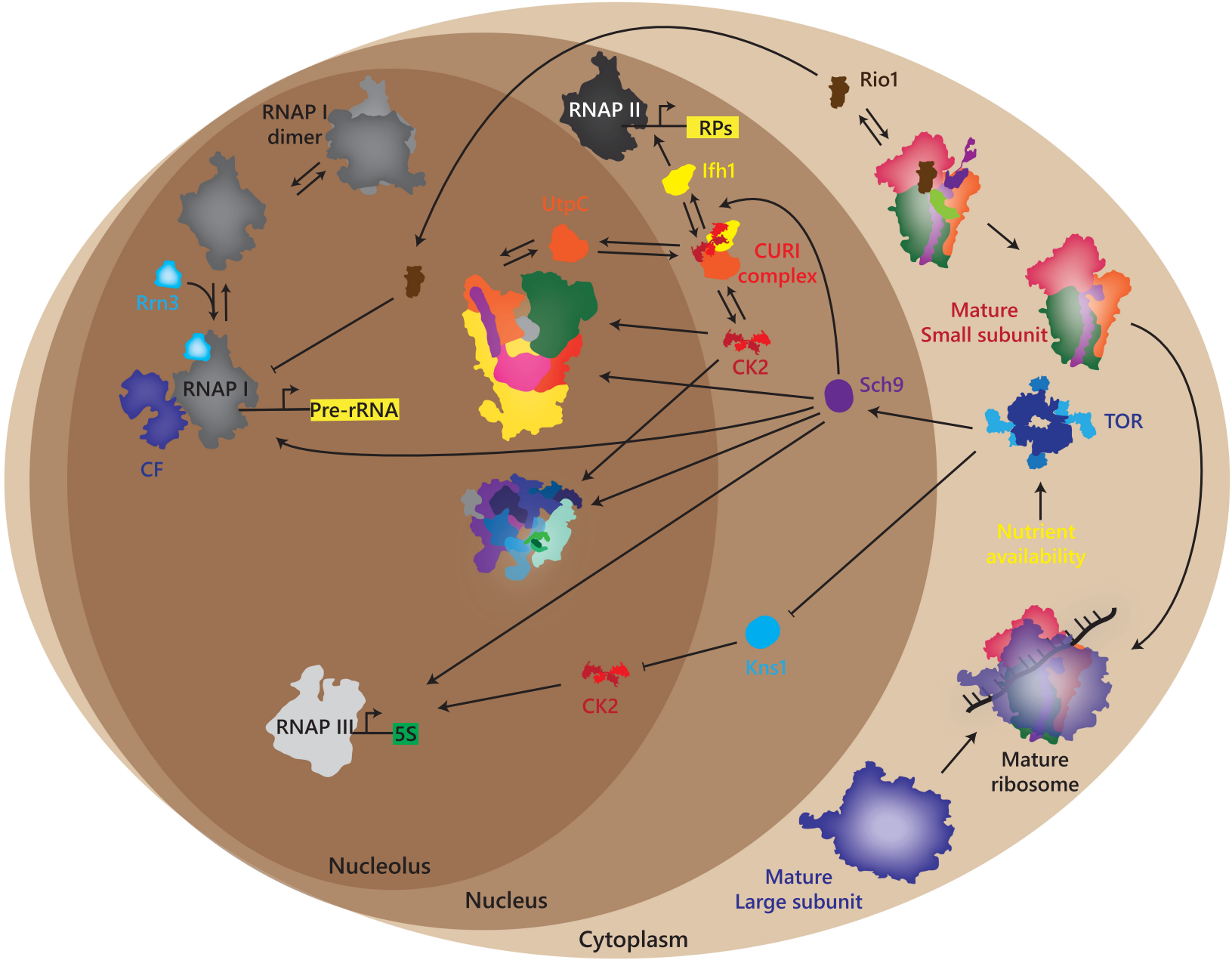

FIGURE 4. Several pathways regulate ribosome biogenesis. TOR is the master regulator of ribosome biogenesis. TOR affects Kns1 and Sch9, which regulate RNAP III transcription, RNAP II transcription of ribosomal protein genes, and RNAP I transcription of pre-rRNA. RNAP I can be silenced by dimerization, which prevents Rrn3 association. Sch9/CK2 also regulate the further maturation of the SSU processome and the LSU processome.

prior to chromosome segregation, which has been suggested to prevent double strand breaks in the DNA during mitosis (Iacovella et al. 2015). Riol's multiple roles in both RNA Pol I regulation and pre-40S particles might suggest a negative feedback mechanism, the details of which are still unclear.

The regulation of pre-rRNA transcription is expected to be coupled to the regulation of ribosome assembly factors and their storage (Fig. 4). Consistent with this, multiple studies have shown that TOR signaling regulates the processing of pre-rRNA. In response to nutrient starvation, or rapamycin treatment, $23 \mathrm{~S}$ and $27 \mathrm{~S}$ species accumulate in a TOR-dependent manner (Talkish et al. 2016; Kos-Braun et al. 2017). Accumulation of precursor RNAs is accompanied by a switch from A2 to A3 cleavage in ITS1 during early processing, in a CK2 dependent manner (Kos-Braun et al. 2017). Importantly, the switch in cleavage pathways is independent of RNA polymerase I transcriptional regulation and must affect ribosome assembly factors directly. This finding is consistent with recent reports that show the accumulation of nucleolar ribo- some assembly intermediates for both SSU and LSU maturation pathways (Chaker-Margot et al. 2017; Sanghai et al. 2017)

Casein kinase 2 (CK2) is also implicated in the regulation of ribosomal protein gene transcription. Multiple studies have shown that UtpC can associate with CK2. Interestingly, all structures of the SSU processome show that CK2 is absent from the EM density or in the mass spectrometry composition of the studied samples. In a recent paper, UtpC was shown to associate with both CK2 and transcriptional factor Ifh1 (Albert et al. 2016) to form the CURI complex. Ifh1 regulates ribosomal protein gene transcription but can be titrated off the promoters by binding to UtpC/CK2. This process is regulated by TOR activity through its downstream effector Sch9. Sch9 deletion is, however, not sufficient to prevent 23S/27S accumulation so other pathways may be involved in halting ribosome assembly. The kinase Kns1, which regulates RNAP III transcription, also links CK2 and TOR pathways. Kns1 is inactivated by TOR and can modulate the activity of CK2 (Sanchez-Casalongue et al. 2015). 


\section{PERSPECTIVES}

Eukaryotic cells invest a staggering amount of energy into the assembly of ribosomes, including more than $60 \%$ of total cellular transcription (Warner 1999). SSU biogenesis illustrates this level of control with the involvement of about 100 factors, whose combined mass exceeds six megadaltons, more than fourfold the mass of the mature SSU. In past years, a wealth of new data has shed light on the roles of many assembly factors, the timing of their association and dissociation with and from ribosome assembly intermediates, and the regulation of the entire process. Cryo-EM structures of early and late intermediates in SSU assembly have given us insights into the functions of approximately 55 of these proteins and will provide a platform for their further biochemical characterization in the future. However, much remains to be learned about SSU assembly and its regulation.

The step that is currently least understood is the transition from the SSU processome to pre-40S particles, which involves a dramatic reorganization of the preribosomal RNA and the dissociation of many assembly factors, most notably the $5^{\prime}$ ETS particle. This transition may require the consorted activity of ATPases, such as Dhr1, Dhr2, Has1, and Rok1, the nuclease Utp24, and the GTPase Bms1. In structures of the SSU processome, U3-pre-rRNA duplexes are heavily protected by a number of ribosome assembly factors. Any access to those RNA duplexes by helicases will require a significant conformational change. It is possible that conformational changes that lead to those processing events could be brought about by Bms1 in a GTP-dependent mechanism. Bms1 is strategically located at the core of the SSU processome between pre-18S domains and makes extensive contact with many factors that pierce through the particle. It is interesting that the GTPase site of Bms1 is solvent exposed in the SSU processome structures. GTPases typically require a GTPase activating protein (GAP) to stimulate GTPase activity. The location of Bms1 therefore raises the possibility of an exogenous factor associating with the SSU processome and inducing GTP hydrolysis. No such factor has been identified, but this would provide an ideal checkpoint for early SSU maturation. Cleavage at the protected A1 site by Utp24 may follow U3-pre-rRNA duplex unwinding.

Another important checkpoint is the formation of 80S-like complexes. These complexes have been proposed to test the ability of the pre-40S particles to perform a translation-like cycle, including translocation (Lebaron et al. 2012; Strunk et al. 2012; Ghalei et al. 2017). Consistent with this idea, the 80S-like complexes also associate with translation factors, including eEF2. Notably, early evidence suggests that mutations of ribosome assembly factors allowing the pre-40S to bypass this step lead to error-prone ribosomes (Ghalei et al. 2017). This would be consistent with this step being an important checkpoint in the quality control of the nascent 40S. Faulty $60 \mathrm{~S}$ subunits that contain an unprocessed ITS2 were shown to be targeted by the nonsense-mediated decay machinery (Sarkar et al. 2017). This may provide us with a clue of what is likely to happen with defective 40S.

Lastly, new regulatory mechanisms have emerged from studies of ribosome assembly. Translation and ribosome assembly have been long-known targets of the TOR complex, but recent insights have shown the extent to which all parts of the assembly are targeted by this pathway. Both large and SSU intermediates can be halted as a consequence of cellular stress through the TOR pathway. This is coupled with the regulation of transcription of ribosomal RNA and proteins. However, while the downstream effectors Sch9, Kns1, and the CK2 pathways are known to be involved, the exact mechanisms by which ribosome assembly intermediates are halted from further processing are still unknown. SSU biogenesis relies on the coordinated action of enzymes and assembly factors. Future research will no doubt provide more snapshots of this dynamic process and highlight the mechanisms by which it is regulated and surveilled.

\section{ACKNOWLEDGMENTS}

I thank Linamarie Miller, Zahra Assur Sanghai, Mirjam Hunziker, and Sebastian Klinge for their help in editing this review and Jonas Barandun for helpful discussions. This work was supported by a PGS D scholarship from Natural Sciences and Engineering Research Council of Canada. I apologize to the authors of the many references that I could not include in this review due to lack of space.

\section{REFERENCES}

Albert B, Knight B, Merwin J, Martin V, Ottoz D, Gloor Y, Bruzzone MJ, Rudner A, Shore D. 2016. A molecular titration system coordinates ribosomal protein gene transcription with ribosomal RNA synthesis. Mol Cell 64: 720-733.

Allmang C, Mitchell P, Petfalski E, Tollervey D. 2000. Degradation of ribosomal RNA precursors by the exosome. Nucleic Acids Res 28: 1684-1691.

Bammert L, Jonas S, Ungricht R, Kutay U. 2016. Human AATF/Che-1 forms a nucleolar protein complex with NGDN and NOL10 required for $40 \mathrm{~S}$ ribosomal subunit synthesis. Nucleic Acids Res 44: 9803-9820.

Barandun J, Chaker-Margot M, Hunziker M, Molloy KR, Chait BT, Klinge S. 2017. The complete structure of the small-subunit processome. Nat Struct Mol Biol 24: 944-953.

Beltrame M, Tollervey D. 1995. Base pairing between U3 and the pre-ribosomal RNA is required for $18 \mathrm{~S}$ rRNA synthesis. $E M B O J$ 14: 4350-4356.

Ben-Shem A, De Loubresse NG, Melnikov S, Jenner L, Yusupova G, Yusupov M. 2011. The structure of the eukaryotic ribosome at 3.0 A resolution. Science 334: 1524-1529.

Bleichert F, Granneman S, Osheim YN, Beyer AL, Baserga SJ. 2006. The PINc domain protein Utp24, a putative nuclease, is required for the early cleavage steps in $18 \mathrm{~S}$ rRNA maturation. Proc Natl Acad Sci 103: 9464-9469.

Chaker-Margot M, Hunziker M, Barandun J, Dill BD, Klinge S. 2015. Stage-specific assembly events of the 6-MDa small-subunit processome initiate eukaryotic ribosome biogenesis. Nat Struct Mol Biol 22: $920-923$.

Chaker-Margot M, Barandun J, Hunziker M, Klinge S. 2017. Architecture of the yeast small subunit processome. Science 355: eaal1880. 
Cheng J, Kellner N, Berninghausen O, Hurt E, Beckmann R. 2017. 3.2$\AA$-resolution structure of the $90 \mathrm{~S}$ preribosome before Al pre-rRNA cleavage. Nat Struct Mol Biol 24: 954-964.

Costello JL, Stead JA, Feigenbutz M, Jones RM, Mitchell P. 2011. The Cterminal region of the exosome-associated protein Rrp47 is specifically required for box $\mathrm{C} / \mathrm{D}$ small nucleolar RNA 3 '-maturation. J Biol Chem 286: 4535-4543.

De la Cruz J, Kressler D, Tollervey D, Linder P. 1998. Doblp (Mtr4p) is a putative ATP-dependent RNA helicase required for the $3^{\prime}$ end formation of $5.8 \mathrm{~S}$ rRNA in Saccharomyces cerevisiae. EMBO J 17: $1128-1140$.

Dragon F, Compagnone-Post PA, Mitchell BM, Porwancher KA, Wehner KA, Wormsley S, Settlage RE, Shabanowitz J, Osheim Y, Beyer AL, et al. 2002. A large nucleolar U3 ribonucleoprotein required for 18S ribosomal RNA biogenesis. Nature 417: 967-970.

Dutca LM, Gallagher JEG, Baserga SJ. 2011. The initial U3 snoRNA:prerRNA base pairing interaction required for pre-18S rRNA folding revealed by in vivo chemical probing. Nucleic Acids Res 39: 5164-5180.

Engel C, Sainsbury S, Cheung AC, Kostrewa D, Cramer P. 2013. RNA polymerase I structure and transcription regulation. Nature 502: 650-655.

Engel C, Plitzko J, Cramer P. 2016. RNA polymerase I-Rrn3 complex at $4.8 \AA$ resolution. Nat Commun 7: 12129.

Engel C, Gubbey T, Neyer S, Sainsbury S, Oberthuer C, Baejen C, Bernecky C, Cramer P. 2017. Structural basis of RNA polymerase I transcription initiation. Cell 169: 120-131.e22.

Fatica A, Tollervey D, Dlakić M. 2004. PIN domain of Noblp is required for $\mathrm{D}$-site cleavage in $20 \mathrm{~S}$ pre-rRNA. RNA 10: 1698-1701.

Faza MB, Chang Y, Occhipinti L, Kemmler S, Panse VG. 2012. Role of Mex67-Mtr2 in the nuclear export of 40S pre-ribosomes. PLoS Genet 8: e1002915.

Ferreira-Cerca S, Sagar V, Schäfer T, Diop M, Wesseling AM, Lu H, Chai E, Hurt E, Laronde-Leblanc N. 2012. ATPase-dependent role of the atypical kinase Rio2 on the evolving pre-40S ribosomal subunit. Nat Struct Mol Biol 19: 1316-1323.

Ferreira-Cerca S, Kiburu I, Thomson E, Laronde N, Hurt E. 2014. Dominant Riol kinase/ATPase catalytic mutant induces trapping of late pre-40S biogenesis factors in 80S-like ribosomes. Nucleic Acids Res 42: 8635-8647.

Fung HYJ, Fu SC, Brautigam CA, Chook YM. 2015. Structural determinants of nuclear export signal orientation in binding to exportin CRM1. eLife 4: e10034.

Ghalei H, Schaub FX, Doherty JR, Noguchi Y, Roush WR, Cleveland JL, Elizabeth Stroupe M, Karbstein K. 2015. Hrr25/CK1ס-directed release of Ltv1 from pre-40S ribosomes is necessary for ribosome assembly and cell growth. J Cell Biol 208: 745-759.

Ghalei H, Trepreau J, Collins JC, Bhaskaran H, Strunk BS, Karbstein K. 2017. Erratum: the ATPase Fap7 tests the ability to carry out translocation-like conformational changes and releases Dim1 during 40S ribosome maturation. Mol Cell 67: 990-1000.e3.

Grandi P, Rybin V, Baßler J, Petfalski E, Strauß D, Marzioch M, Schäfer T, Kuster B, Tschochner H, Tollervey D, et al. 2002. $90 \mathrm{~S}$ pre-ribosomes include the $35 \mathrm{~S}$ pre-rRNA, the U3 snoRNP, and $40 \mathrm{~S}$ subunit processing factors but predominantly lack $60 \mathrm{~S}$ synthesis factors. Mol Cell 10: 105-115.

Granneman S, Lin CY, Champion EA, Nandineni MR, Zorca C, Baserga SJ. 2006. The nucleolar protein Esf2 interacts directly with the $\mathrm{DExD} / \mathrm{H}$ box RNA helicase, $\mathrm{Dbp} 8$, to stimulate ATP hydrolysis. Nucleic Acids Res 34: 3189-3199.

Granneman S, Petfalski E, Swiatkowska A, Tollervey D. 2010. Cracking pre- $40 \mathrm{~S}$ ribosomal subunit structure by systematic analyses of RNAprotein cross-linking. EMBO J 29: 2026-2036.

Han Y, Yan C, Nguyen THD, Jackobel AJ, Ivanov I, Knutson BA, He Y. 2017. Structural mechanism of ATP-independent transcription initiation by RNA polymerase I. eLife 6: e27414.

Hayama R, Rout MP, Fernandez-Martinez J. 2017. The nuclear pore complex core scaffold and permeability barrier: variations of a common theme. Curr Opin Cell Biol 46: 110-118.
Heuer A, Thomson E, Schmidt C, Berninghausen O, Becker T, Hurt E, Beckmann R. 2017. Cryo-EM structure of a late pre-40S ribosomal subunit from Saccharomyces cerevisiae. eLife 6: e30189.

Holzer S, Ban N, Klinge S. 2013. Crystal structure of the yeast ribosomal protein rpS3 in complex with its chaperone Yar1. J Mol Biol 425: $4154-4160$

Hunziker M, Barandun J, Petfalski E, Tan D, Delan-Forino C, Molloy KR, Kim KH, Dunn-Davies H, Shi Y, Chaker-Margot M, et al. 2016. UtpA and UtpB chaperone nascent pre-ribosomal RNA and U3 snoRNA to initiate eukaryotic ribosome assembly. Nat Commun 7: 12090.

Iacovella MG, Golfieri C, Massari LF, Busnelli S, Pagliuca C, Dal Maschio M, Infantino V, Visintin R, Mechtler K, Ferreira-Cerca S, et al. 2015. Riol promotes rDNA stability and downregulates RNA polymerase I to ensure rDNA segregation. Nat Commun 6: 6643.

Klinge S, Voigts-Hoffmann F, Leibundgut M, Arpagaus S, Ban N. 2011. Crystal structure of the eukaryotic $60 \mathrm{~S}$ ribosomal subunit in complex with initiation factor 6. Science 334: 941-948.

Kornprobst M, Turk M, Kellner N, Cheng J, Flemming D, Koš-Braun I, Koš M, Thoms M, Berninghausen O, Beckmann R, et al. 2016. Architecture of the $90 \mathrm{~S}$ pre-ribosome: a structural view on the birth of the eukaryotic ribosome. Cell 166: 380-393.

Koš M, Tollervey D. 2005. The putative RNA helicase Dbp4p is required for release of the U14 snoRNA from preribosomes in Saccharomyces cerevisiae. Mol Cell 20: 53-64.

Kos-Braun IC, Jung I, Koš M. 2017. Tor 1 and CK2 kinases control a switch between alternative ribosome biogenesis pathways in a growth-dependent manner. PLoS Biol 15: e2000245.

Kutay U, Guttinger S. 2005. Leucine-rich nuclear export signals: born to be weak. Trends Cell Bio 15: 121-124.

Lebaron S, Schneider C, Van Nues RW, Swiatkowska A, Walsh D, Böttcher B, Granneman S, Watkins NJ, Tollervey D. 2012. Proofreading of pre-40S ribosome maturation by a translation initiation factor and 60S subunits. Nat Struct Mol Biol 19: 744-753.

Lebaron S, Segerstolpe $\AA$, French SL, Dudnakova T, de lima Alves F, Granneman S, Rappsilber J, Beyer AL, Wieslander L, Tollervey D. 2013. Rrp5 binding at multiple sites coordinates Pre-rRNA processing and assembly. Mol Cell 52: 707-719.

Liang WQ, Fournier MJ. 1995. U14 base-pairs with 18S rRNA: a novel snoRNA interaction required for rRNA processing. Genes Dev 9: 2433-2443.

Lin J, Lu J, Feng Y, Sun M, Ye K. 2013. An RNA-binding complex involved in ribosome biogenesis contains a protein with homology to tRNA CCA-adding enzyme. PLoS Biol 11: e1001669.

Marmier-Gourrier N, Cléry A, Schlotter F, Senty-Ségault V, Branlant C. 2011. A second base pair interaction between U3 small nucleolar RNA and the $5^{\prime}$-ETS region is required for early cleavage of the yeast pre-ribosomal RNA. Nucleic Acids Res 39: 9731-9745.

McCaughan UM, Jayachandran U, Shchepachev V, Chen ZA, Rappsilber J, Tollervey D, Cook AG. 2016. Pre-40S ribosome biogenesis factor Tsr1 is an inactive structural mimic of translational GTPases. Nat Commun 7: 11789.

Miller OL, Beatty BR. 1969. Visualization of nucleolar genes. Science 164: 955-957.

Mitterer V, Gantenbein N, Birner-Gruenberger R, Murat G, Bergler H, Kressler D, Pertschy B. 2016. Nuclear import of dimerized ribosomal protein Rps3 in complex with its chaperone Yar1. Sci Rep 6: 36714.

Oeffinger M, Dlakić M, Tollervey D. 2004. A pre-ribosome-associated HEAT-repeat protein is required for export of both ribosomal subunits. Genes Dev 18: 196-209.

Pérez-Fernández J, Roman A, De Las Rivas J, Bustelo XR, Dosil M. 2007. The $90 \mathrm{~S}$ preribosome is a multimodular structure that is assembled through a hierarchical mechanism. Mol Cell Biol 27: 5414-5429.

Pérez-Fernández J, Martín-Marcos P, Dosil M. 2011. Elucidation of the assembly events required for the recruitment of Utp20, Imp4 and Bms1 onto nascent pre-ribosomes. Nucleic Acids Res 39: 8105-8121.

Pilsl M, Crucifix C, Papai G, Krupp F, Steinbauer R, Griesenbeck J, Milkereit P, Tschochner H, Schultz P. 2016. Structure of the 
initiation-competent RNA polymerase I and its implication for transcription. Nat Commun 7: 12126.

Rabl J, Leibundgut M, Ataide SF, Haag A, Ban N. 2011. Crystal structure of the eukaryotic $40 \mathrm{~S}$ ribosomal subunit in complex with initiation factor 1. Science 331: 730-736.

Sadian Y, Tafur L, Kosinski J, Jakobi AJ, Wetzel R, Buczak K, Hagen WJ, Beck M, Sachse C, Müller CW. 2017. Structural insights into transcription initiation by yeast RNA polymerase I. EMBO $J$ 36: 2698-2709.

Sanchez-Casalongue ME, Lee J, Diamond A, Shuldiner S, Moir RD, Willis IM. 2015. Differential phosphorylation of a regulatory subunit of protein kinase CK2 by target of rapamycin complex 1 signaling and the Cdc-like kinase Kns1. J Biol Chem 290: 7221-7233.

Sanghai ZA, Miller L, Molloy KR, Barandun J, Hunziker M, ChakerMargot M, Wang J, Chait BT, Klinge S. 2017. Modular assembly of the nucleolar large subunit processome. bioRxiv doi: 10.1101/ 223412.

Sardana R, Zhu J, Gill M, Johnson AW. 2014. Physical and functional interaction between the methyltransferase Bud23 and the essential DEAH-box RNA helicase Ecm16. Mol Cell Biol 34: 2208-2220.

Sardana R, Liu X, Granneman S, Zhu J, Gill M, Papoulas O, Marcotte EM, Tollervey D, Correll CC, Johnson AW. 2015. The DEAH-box helicase Dhr1 dissociates U3 from the pre-rRNA to promote formation of the central pseudoknot. PLoS Biol 13: e1002083.

Sarkar A, Thoms M, Barrio-Garcia C, Thomson E, Flemming D, Beckmann R, Hurt E. 2017. Preribosomes escaping from the nucleus are caught during translation by cytoplasmic quality control. Nat Struct Mol Biol 24: 1107-1115.

Scaiola A, Peña C, Weisser M, Böhringer D, Leibundgut M, KlingaufNerurkar P, Gerhardy S, Panse VG, Ban N. 2018. Structure of a eukaryotic cytoplasmic pre-40S ribosomal subunit. EMBO J 37: e98499.

Schäfer T, Strauß D, Petfalski E, Tollervey D, Hurt E. 2003. The path from nucleolar $90 \mathrm{~S}$ to cytoplasmic $40 \mathrm{~S}$ pre-ribosomes. EMBO J 22: $1370-1380$.

Schäfer T, Maco B, Petfalski E, Tollervey D, Böttcher B, Aebi U, Hurt E. 2006. Hrr25-dependent phosphorylation state regulates organization of the pre-40S subunit. Nature 441: 651-655.

Schneider DA. 2012. RNA polymerase I activity is regulated at multiple steps in the transcription cycle: recent insights into factors that influence transcription elongation. Gene 493: 176-184.

Schütz S, Fischer U, Altvater M, Nerurkar P, Peña C, Gerber M, Chang Y, Caesar S, Schubert OT, Schlenstedt G, et al. 2014. A RanGTP-independent mechanism allows ribosomal protein nuclear import for ribosome assembly. eLife 3: e03473.

Segerstolpe $\AA$, Granneman S, Björk P, De Lima Alves F, Rappsilber J, Andersson C, Högbom M, Tollervey D, Wieslander L. 2013. Multiple RNA interactions position Mrd1 at the site of the small subunit pseudoknot within the $90 \mathrm{~S}$ pre-ribosome. Nucleic Acids Res 41: $1178-1190$.

Sharma K, Tollervey D. 1999. Base pairing between U3 small nucleolar RNA and the $5^{\prime}$ end of $18 \mathrm{~S}$ rRNA is required for pre-rRNA processing. Mol Cell Biol 19: 6012-6019.
Soltanieh S, Lapensée M, Dragon F. 2014. Nucleolar proteins Bfr2 and Enp2 interact with DEAD-box RNA helicase Dbp4 in two different complexes. Nucleic Acids Res 42: 3194-3206.

Soltanieh S, Osheim YN, Spasov K, Trahan C, Beyer AL, Dragon F. 2015. DEAD-box RNA helicase Dbp4 is required for small-subunit processome formation and function. Mol Cell Biol 35: 816-830.

Strunk BS, Novak MN, Young CL, Karbstein K. 2012. A translation-like cycle is a quality control checkpoint for maturing $40 \mathrm{~S}$ ribosome subunits. Cell 150: 111-121.

Sun Q, Zhu X, Qi J, An W, Lan P, Tan D, Chen R, Wang B, Zheng S, Zhang C, et al. 2017. Molecular architecture of the $90 \mathrm{~S}$ small subunit pre-ribosome. eLife 6: e22086.

Talkish J, Biedka S, Jakovljevic J, Zhang J, Tang L, Strahler JR, Andrews PC, Maddock JR, Woolford JL. 2016. Disruption of ribosome assembly in yeast blocks cotranscriptional pre-rRNA processing and affects the global hierarchy of ribosome biogenesis. RNA 22: 852-866.

Thoms M, Thomson E, Baßler J, Gnädig M, Griesel S, Hurt E. 2015. The exosome is recruited to RNA substrates through specific adaptor proteins. Cell 162: 1029-1038.

Torreira E, Louro JA, Pazos I, González-Polo N, Gil-Carton D, Duran AG, Tosi S, Gallego O, Calvo O, Fernández-Tornero C. 2017. The dynamic assembly of distinct RNA polymerase I complexes modulates rDNA transcription. eLife 6: e20832.

Turowski TW, Lebaron S, Zhang E, Peil L, Dudnakova T, Petfalski E, Granneman S, Rappsilber J, Tollervey D. 2014. Rio1 mediates ATP-dependent final maturation of $40 \mathrm{~S}$ ribosomal subunits. Nucleic Acids Res 42: 12189-12199.

Udem SA, Warner JR. 1972. Ribosomal RNA synthesis in Saccharomyces cerevisiae. J Mol Biol 65: 227-242.

Venema J, Vos HR, Faber AW, Van Venrooij WJ, Raué HA. 2000. Yeast Rrp9p is an evolutionarily conserved U3 snoRNP protein essential for early pre-rRNA processing cleavages and requires box $\mathrm{C}$ for its association. RNA 6: 1660-1671.

Wang B, Ye K. 2016. Nop9 binds the central pseudoknot region of $18 \mathrm{~S}$ rRNA. Nucleic Acids Res 45: 3559-3567.

Warner JR. 1999. The economics of ribosome biosynthesis in yeast. Trends Biochem Sci 24: 437-440.

Watkins NJ, Bohnsack MT. 2012. The box C/D and H/ACA snoRNPs: key players in the modification, processing and the dynamic folding of ribosomal RNA. Wiley Interdiscip Rev RNA 3: 397-414.

Wells GR, Weichmann F, Colvin D, Sloan KE, Kudla G, Tollervey D, Watkins NJ, Schneider C. 2016. The PIN domain endonuclease Utp24 cleaves pre-ribosomal RNA at two coupled sites in yeast and humans. Nucleic Acids Res 44: 5399-5409.

Wells GR, Weichmann F, Sloan KE, Colvin D, Watkins NJ, Schneider C. 2017. The ribosome biogenesis factor yUtp23/hUTP23 coordinates key interactions in the yeast and human pre-40S particle and hUTP23 contains an essential PIN domain. Nucleic Acids Res 45: 4796-4809.

Zhang L, Wu C, Cai G, Chen S, Ye K. 2016. Stepwise and dynamic assembly of the earliest precursors of small ribosomal subunits in yeast. Genes Dev 30: 718-732.

[Malik Chaker-Margot was the winner of the 2017 RNA Society/Scaringe Award.] 

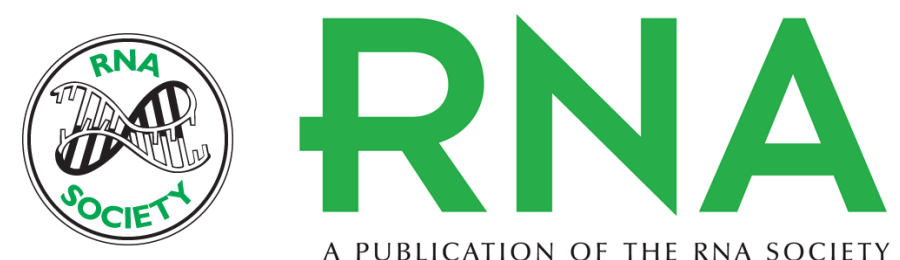

A PUBLICATION OF THE RNA SOCIETY

\title{
Assembly of the small ribosomal subunit in yeast: mechanism and regulation
}

\author{
Malik Chaker-Margot
}

RNA 2018 24: 881-891 originally published online April 30, 2018

Access the most recent version at doi:10.1261/rna.066985.118
References This article cites 80 articles, 25 of which can be accessed free at: http://rnajournal.cshlp.org/content/24/7/881.full.html\#ref-list-1
Creative This article is distributed exclusively by the RNA Society for the first 12 months after the Commons full-issue publication date (see http://rnajournal.cshlp.org/site/misc/terms.xhtml). After 12 License months, it is available under a Creative Commons License (Attribution-NonCommercial 4.0 International), as described at http://creativecommons.org/licenses/by-nc/4.0/.

Email Alerting Receive free email alerts when new articles cite this article - sign up in the box at the Service top right corner of the article or click here.

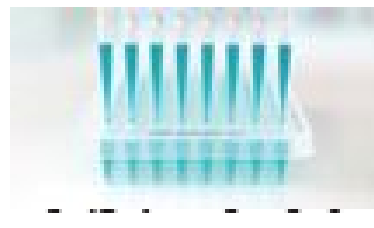

\section{Providing Precise Solutions for} your research.

To subscribe to RNA go to:

http://rnajournal.cshlp.org/subscriptions 